\title{
Proposal of a Component to Restrict Dust from Entering an Oil Hydraulic System through an Oil Hydraulic Cylinder
}

\author{
Etinot Betty ${ }^{1}$ and Yasuo Sakurai ${ }^{2}$ \\ 1. Machining Department, Nakawa Vocational Training College, Kampala 20121, Uganda \\ 2. Department of Mechanical Engineering, Ashikaga University, Omae-cho, Ashikaga, Tochigi 326-8558, Japan
}

\begin{abstract}
This research proposes a component to restrict dust from entering an oil hydraulic system through the rod-seal clearance of an oil hydraulic cylinder. The oil hydraulic cylinder as one of main parts of the hydraulic system, controls position of load by reciprocation. For example, on construction machines such as excavators and graders, the cylinder controls position of folk lift, crane and bucket. However, during operation, dust enters the cylinder, wears seals, causes fluid degradation and affects lubrication of valves, pumps and other parts of hydraulic system. This increases breakdown rate of cylinder and entire system. Thus, it seems necessary to reduce on intrusion of dust into the system via the hydraulic cylinder. In this research, we made an experimental apparatus to simulate intrusion of the dust into system. Results proved that the apparatus is a suitable simulator to realize the intrusion. The proposed component to restrict dust from entering cylinder was fabricated and its performance tested when inserted with various elastic rings. The component gave tremendous results when inserted with O-ring seal and a plastic nylon washer, and can be retrofitted on new and old hydraulic cylinders. It is an appropriate technology especially in developing countries where dust is still a major concern.
\end{abstract}

Key words: Appropriate technology, oil-hydraulic system, oil hydraulic cylinder, rod-seal clearance, component to restrict dust.

\section{Introduction}

Oil hydraulic systems are drive mechanisms in which energy is conveyed from one part of the system to another by use of pressurized oil. They are applicable in a wide variety of fields specifically in engineering, from small assembly processes to integrated steel and paper mill applications. These systems consist of many parts such as pumps, valves, accumulators and oil hydraulic cylinders. The oil hydraulic cylinder is a linear actuator powered by hydraulic energy and as one of the main actuators; it controls the position of the load by retracting and extending linearly. For example, in construction, the cylinder positions the folk lift, cranes, backhoes and

Corresponding author: Etinot Betty, instructor, master (Ms.) of engineering-information science and manufacturing engineering, research field: oil hydraulics. buckets on excavators and graders. In manufacturing, it positions the table of grinding and cutting machines. This therefore means that many of these machines would be incomplete without the oil hydraulic cylinder. However, during working conditions, dust is one of the environmental conditions that accelerate the breakdown of the cylinder. Zhao et al. [1] reported that the status of the cylinder affects the system performance. Zhong [2] observed that the presence of dust particles destroyed the lubricating conditions of a piston cylinder liner, speeded up wear of the liner especially on the thrust side and aggravated the local wear.

When dust is extremely small, it enters into the oil-hydraulic cylinder through the rod-seal clearance. This wears the cylinder components especially the seals and contaminates the oil hydraulic fluid. Fig.1a shows a motor grader that is out of service because 


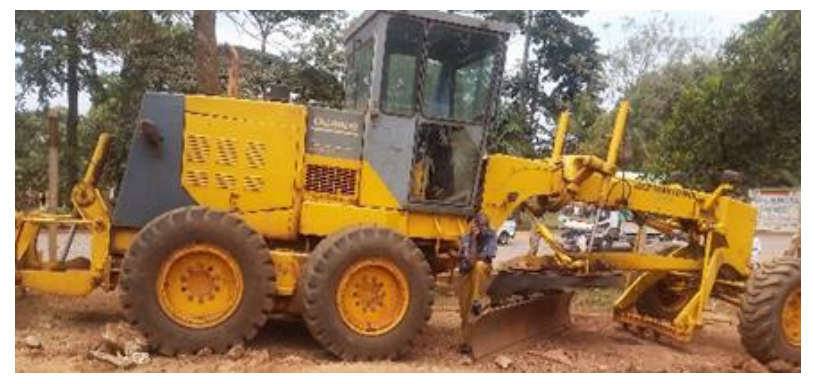

(a) Motor grader

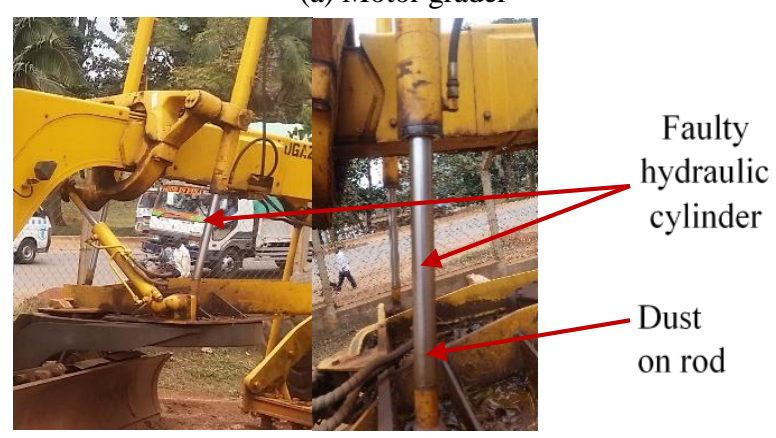

(b) Hydraulic cylinders with worn seals

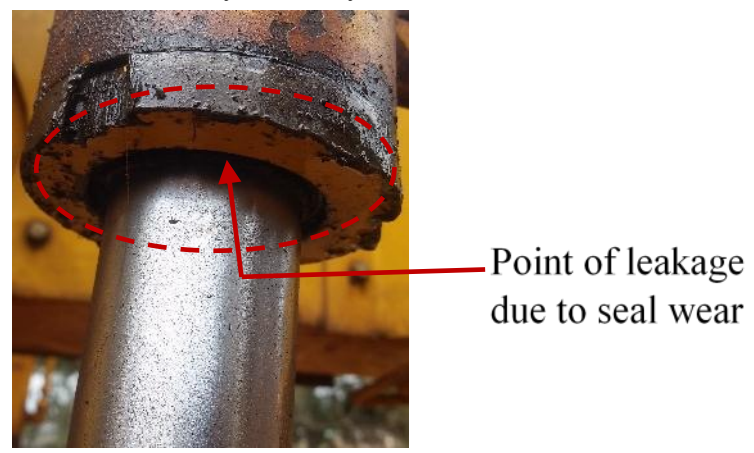

(c) Leakage through the rod-seal clearance

Fig. 1 Out of service motor grader due to faulty condition of one of its oil hydraulic cylinders.

of one of its oil hydraulic cylinders (Fig. 1b) becoming faulty. Investigations indicated that the failure was because of dust from the environment and extreme heat, which affected the seals leading to their wear and leakage through the rod seal clearance (Fig. 1c).

On the other hand, Related fluid power limited [3] reported that, contamination in the oil can cause wear to components and reduce the ability of the hydraulic fluid to lubricate, having a direct bearing on the hydraulic system reliability and performance. According to Flow Ezy filter notes [4], unless measures are taken to remove certain amounts of particles in hydraulic fluids, the dirt levels will continue to increase until a component and the entire system fail.
Breakdown of oil hydraulic systems due to dust occurs very often in underdeveloped and developing countries such as in sub-Saharan Africa where dust is still a big threat. Therefore, it is necessary to develop a component for controlling dust from entering the oil hydraulic system to improve on the reliability of hydraulic machines. By applying an appropriate technology, a component to restrict dust from entering an oil hydraulic system through an oil hydraulic cylinder should be developed.

In this study, a component to prevent dust from entering the oil hydraulic system through the rod-seal clearance of the oil hydraulic cylinder is proposed, whose structure should be simple. The proposed component is fabricated and some experiments to make clear its performance are carried out. To carry out these experiments, a system to simulate the intrusion of dust is developed too.

\section{Proposed Component to Restrict Dust}

\subsection{Mechanism of Intrusion of Dust into Oil Hydraulic Cylinder and System}

The oil hydraulic cylinder has a dust seal as shown in Fig. 2a. When dust falls on to the cylinder rod, in case of small particles, the rod carries this dust to the inside of the cylinder during extension and retraction through the extremely narrow clearance between the dust seal and the rod as shown in Fig. 2b. This contaminates the hydraulic fluid and damages the oil hydraulic cylinder and system. Parker hydraulics [5] stated that abrasive particles suspended in the fluid could damage the seal and the piston rod surface while airborne contamination can be drawn into a cylinder via a faulty wiper seal.

\subsection{Proposed Mechanism and Component to Restrict Dust from Entering the Oil Hydraulic Cylinder}

To prevent dust from entering the oil hydraulic cylinder by the mechanism shown in Fig. $2 b$, it is necessary to make the clearance between the rod and seal zero. To realize this, an elastic ring of which the 


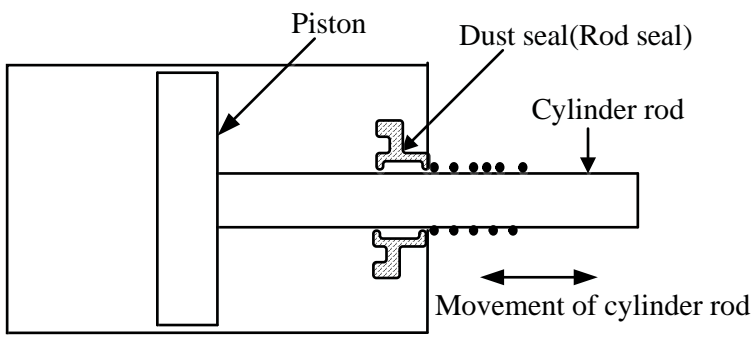

(a) Oil hydraulic cylinder

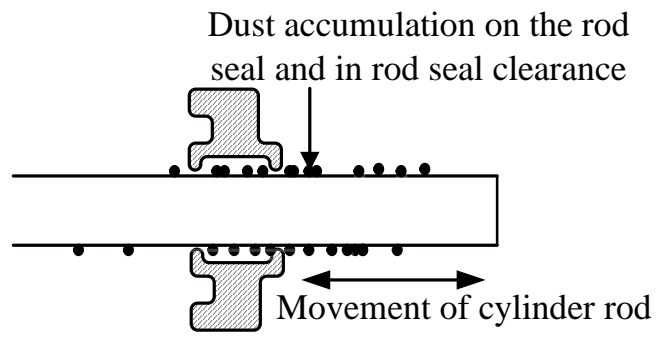

(b) Dust intrusion into cylinder

Fig. 2 Mechanism of dust accumulation and entry through the rod clearance.

inside diameter is same as that of the cylinder rod is used. The ring should be tight in its groove during reciprocation motion of the rod. In addition, the phenomenon shown in Fig. $2 b$ occurs at specific locations such as sub-Saharan Africa. Therefore, it is desirable that the proposed component can be retrofitted to an oil hydraulic cylinder. Figs. 3 and 4 show the schematic structure of the component to prevent dust from entering the oil hydraulic system through the rod-seal clearance of the hydraulic cylinder. The structure of the component is as follows.

The component has two main parts, Fig. 3 and an elastic ring. The main steel metal body (Fig. 3a) serves as a housing to the elastic ring. It has a groove in which the ring is inserted. The internal diameter of the groove is almost same as outside diameter of the ring and internal diameter of the ring is same as diameter of the cylinder rod. On the steel metal body, the side opposite to the groove has a large female screw to allow for fastening of the component on to the male screw of rod side end of the oil hydraulic cylinder. The steel metal lid (Fig. 3b) is fixed to the housing to cover and secure the elastic ring in its groove. The lid is secured firmly to the housing by use

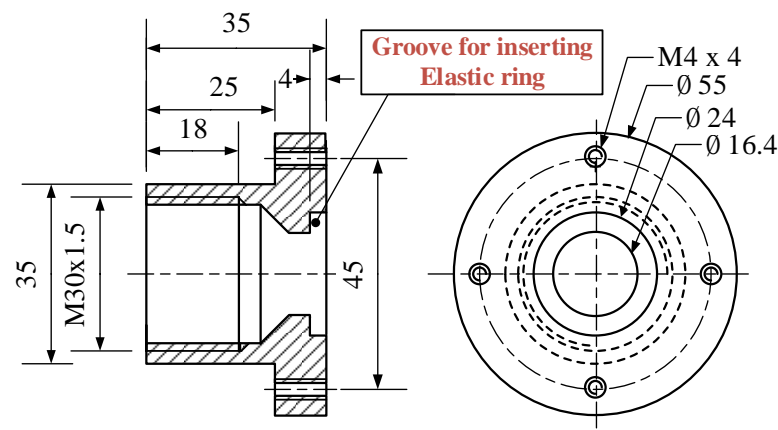

(a) Main steel metal body (housing)

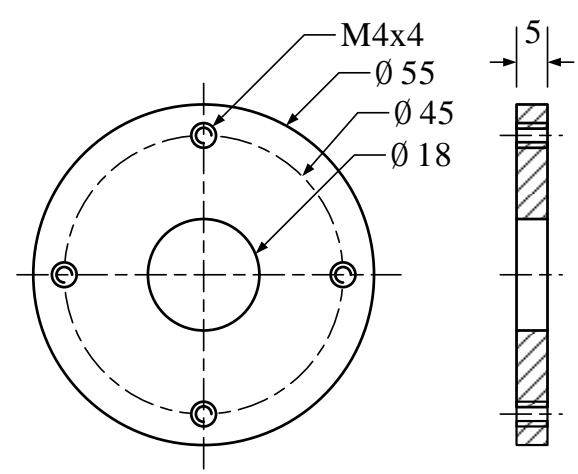

(b) Steel metal lid

Fig. 3 Main parts of the proposed component.

of female screws and bolts. Fig. 4a is assembly drawing of the component while Fig. $4 \mathrm{~b}$ shows the component as it would appear on the oil hydraulic cylinder with zero clearance between the rod and ring. In this component, attention should be paid to the friction characteristics between the elastic ring and the rod and the durability of the ring. In this study, through some experiments, these characteristics are made clear.

\section{Experimental Apparatus to Simulate the Intrusion of Dust}

\subsection{Proposed Experimental Apparatus}

Prior to the experiment to make clear the validity of the proposed component to restrict dust, the state to enter dust into oil hydraulic cylinder should be reproduced. Therefore, the simulator to accomplish it is proposed. To make the above-mentioned state, it is necessary to move oil hydraulic cylinder many times. Furthermore, since this study is the first step to 


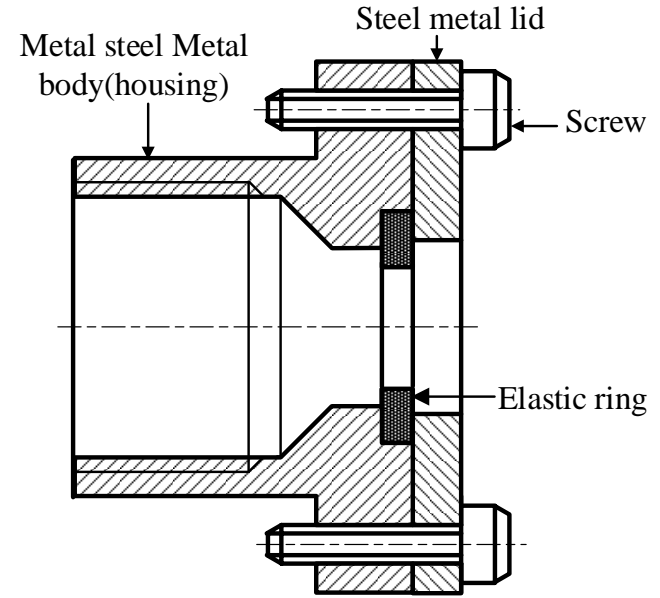

(a) Assembly drawing of the component

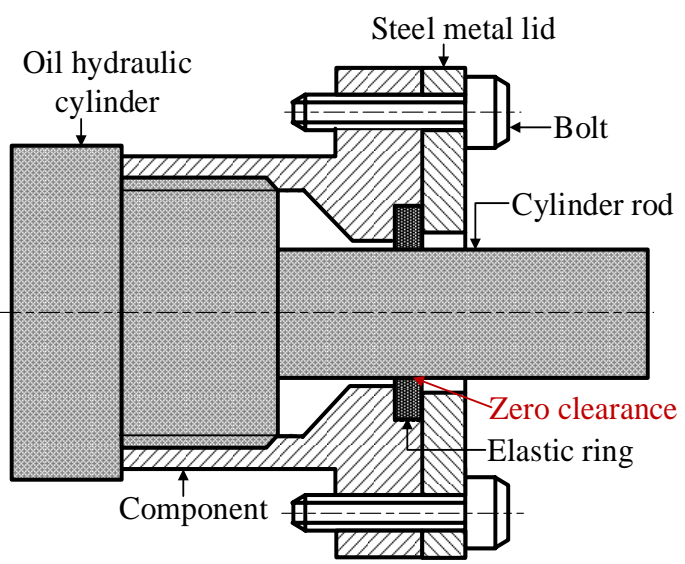

(b) Zero clearance between the rod and ring

Fig. 4 Proposed component and illustration of zero clearance.

develop the component to restrict dust, it seems to be desirable to start the development from the case where the pressure of oil hydraulic system is low. As a result, an electric cylinder is employed as the drive unit.

Fig. 5 shows the schematic diagram and photo of the proposed experimental apparatus to simulate the intrusion of dust into the oil hydraulic system through an oil hydraulic cylinder. It consists mainly of two parts, an oil hydraulic circuit unit and a drive unit. The oil hydraulic circuit consists of oil hydraulic cylinder, niddle valve, hydraulic filter, and tank. Pressure transducers are connected at the rod side end and head side end of the oil hydraulic cylinder, to monitor pressure of the hydraulic system from a personal computer with aid of a data logging system. By adjusting the opening area of the niddle valve, it is

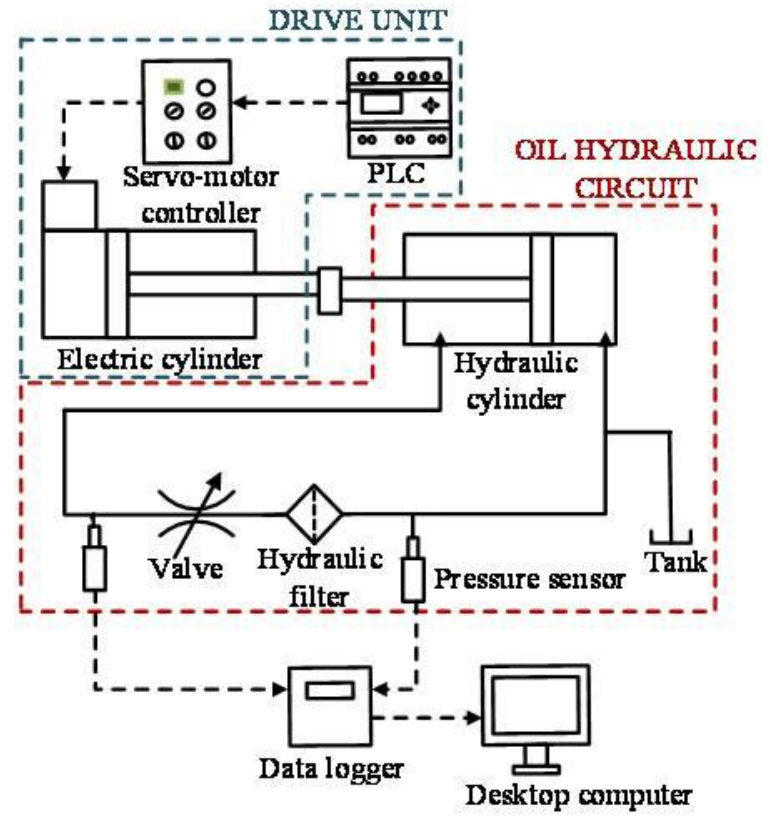

(a) Schematic diagram

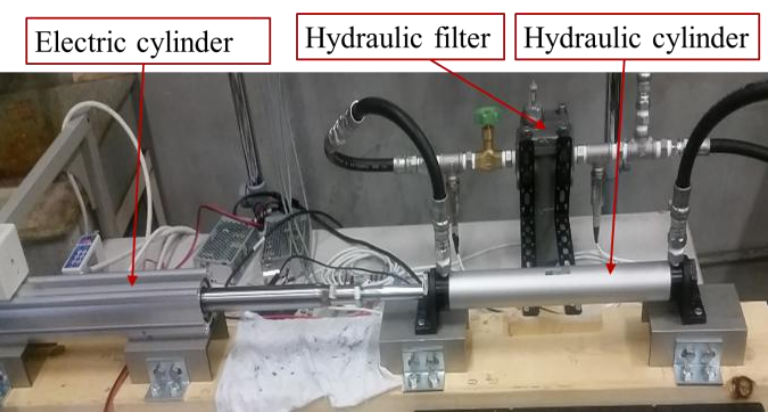

(b) Photo

Fig. 5 Experimental apparatus.

possible to regulate the fluid flow within the system and hence pressure. The drive unit consists of an electric cylinder, microcontroller and PLC (programmable logic controller). The electric cylinder rod is connected to the oil hydraulic cylinder rod by use of a metal screw with external and internal threads. Thus, by controlling the movement of the electric cylinder using a microcontroller and PLC, the hydraulic cylinder could be moved.

\subsection{Experimental Method and Results}

Yuwono et al. [6] measured the particle size distribution of dust fall and total suspended particles for diameter of $<2.5 \mu \mathrm{m}, 2.5-10 \mu \mathrm{m}$ and $>10 \mu \mathrm{m}$ in a given soil sample without land cover and after growth 
of land cover. He found out that the total particle size distribution of dust fall and total suspended particles for diameter of $<2.5 \mu \mathrm{m}, 2.5-10 \mu \mathrm{m}$ and $>10 \mu \mathrm{m}$ were $60.8 \%, 35.3 \%$ and $3.9 \%$ without land cover and $36.4 \%, 59.1 \%$ and $4.5 \%$ with land cover respectively. Thus in this research, silicon carbide dust powder (Fig. 6 ), with a mean particle size of 9-15 $\mu$ m was used because particle size of 9 and $10 \mu \mathrm{m}$ falls within Yuwono's range of $2.5-10 \mu \mathrm{m}$ which is the main particle size with land cover. A light sticky dust paste (Fig. 7), was prepared out of the powder by mixing it with small amounts of clean, new hydraulic oil. The opening area of the valve was adjusted to a pressure of nearly $0.17 \mathrm{MPa}$. The hydraulic cylinder stroke was set to $400 \mathrm{~mm}$ and lasted $3.3 \mathrm{sec}$. Several experiments with varying timeframe were carried out until the total distance of the hydraulic cylinder was $100 \mathrm{~km}$. In each experiment, the following procedures were followed:

First, dust paste was smeared on the rod of the oil hydraulic cylinder. The experiment was set to run. Then, dust paste was applied on the cylinder rod for every 2-3 minutes interval throughout the entire experiment. Maximum pressure respectively at the rod side and head side ends of the cylinder was measured

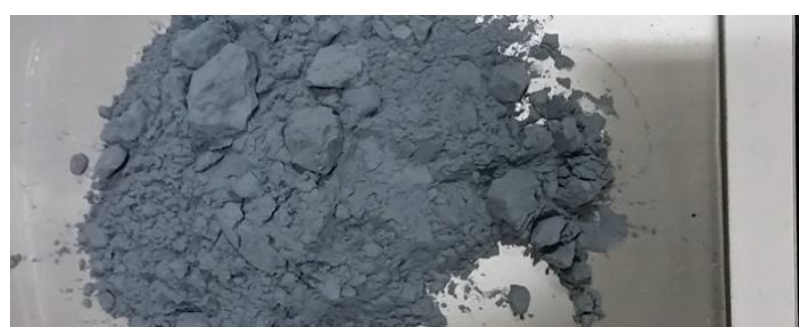

Fig. 6 Silicone carbide dust powder.

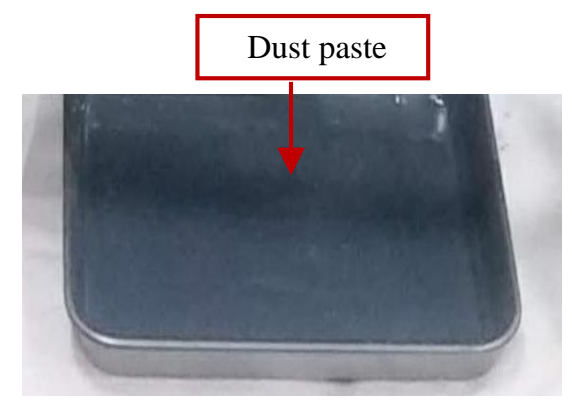

Fig. 7 Dust paste made from the silicone powder.
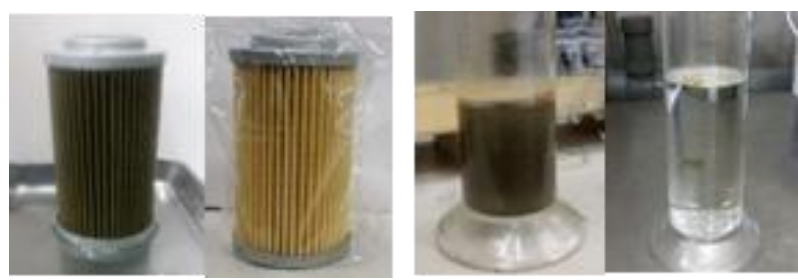

Fig. 8 Comparison of filter element and oil used in test with the new ones.

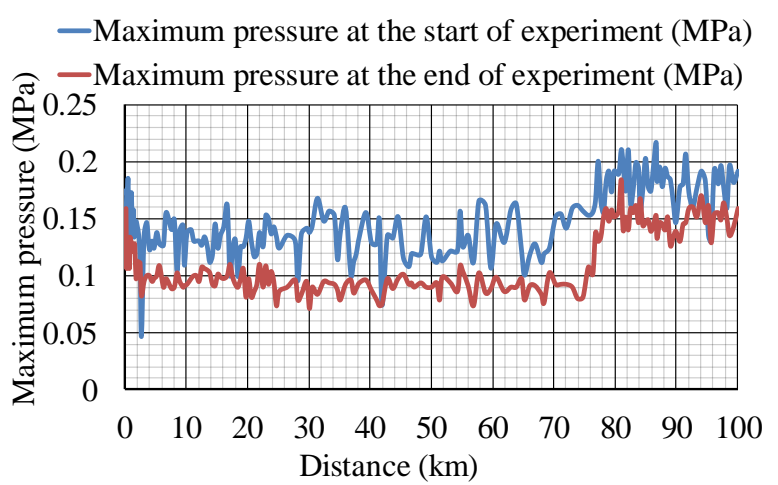

Fig. 9 Maximum pressure at the rod side of the oil hydraulic cylinder.

both at the beginning and end of each experiment. The distance for each experiment was recorded and the cumulative total distance for all experiments was calculated.

Fig. 8 shows the results of filter element and hydraulic oil while Fig. 9 shows results of the maximum pressure at the rod side of the oil hydraulic cylinder. The filter element turned grey colour compared with the yellow colour of the new one. Hydraulic oil also turned grey compared with clear colour of the new oil. This is because of the dust that entered the oil hydraulic system through the clearance of the rod of the hydraulic cylinder. The pressure fluctuated constantly until a distance of about $70 \mathrm{~km}$ and increased afterwards. The increase was because when dust entered the oil hydraulic system, it increased the resistance of the filter element and hydraulic oil reducing their performance. Basing on the results, simulation of intrusion of dust into the hydraulic system through the rod-seal clearance of an oil hydraulic cylinder was successful.

Consequently, it is necessary to develop a component to reduce entry of dust into the hydraulic 
cylinder through the rod-seal clearance, to maintain the performance of an oil hydraulic system and to prolong the life of the hydraulic system components. As a result, the experimental apparatus can be employed to test the performance of the proposed component.

\section{Experiment for Proposed Component}

\subsection{Experimental Apparatus and Method}

Following successful simulation of intrusion of dust into the hydraulic system, the proposed component was fabricated. To test its performance in preventing dust from entering the system through the rod-seal clearance of the hydraulic cylinder, the component parts were assembled and the component connected to the rod side end of the hydraulic cylinder following steps 1-6 in Fig. 10. During the test, the experimental apparatus, methods and procedures for simulating the intrusion of dust into the system were used. However, with the component, the opening area of the valve was adjusted to a pressure of $0.23 \mathrm{MPa}$.

\subsection{Elastic Rings}

The component was tested when inserted with various elastic rings separately: that is dust soft wiper

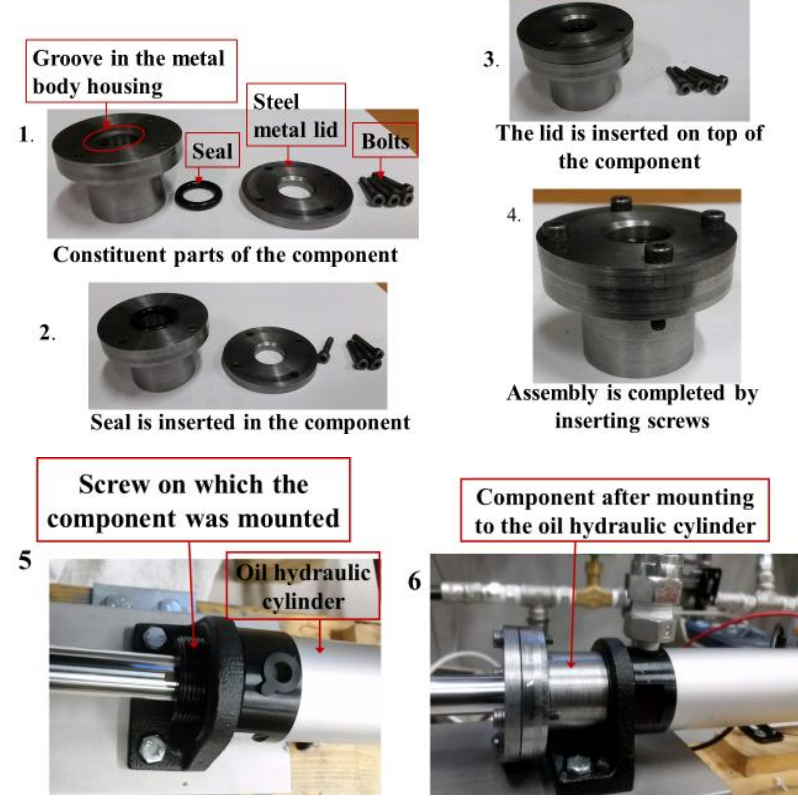

Fig. 10 Assembly and mounting steps of the component.

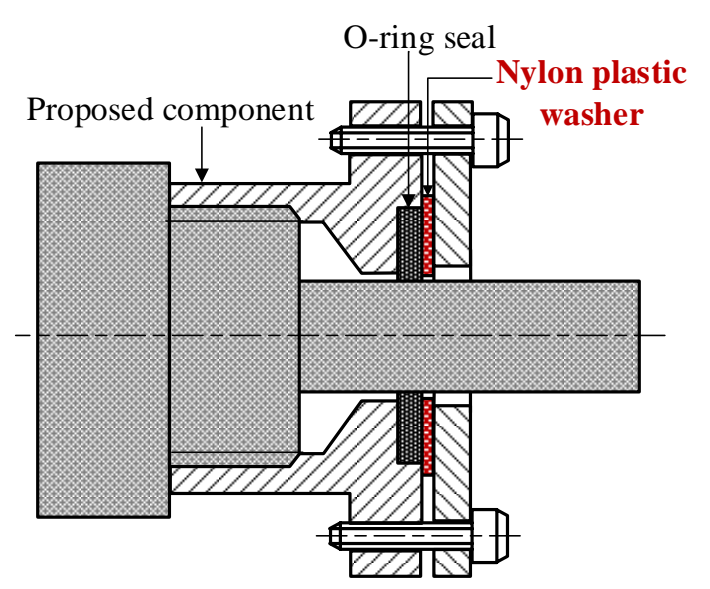

Fig. 11 Way of inserting washer in component.

seal (https://www.monotaro.sg/g/01013258/), silicon rubber seal, O-ring seal of nitrile rubber and O-ring seal combined with a plastic nylon washer, separately. The size of dust soft wiper seal is $\varnothing 24 \times \emptyset 16 \times 3 \mathrm{~mm}$ and it is made of polyester fiber composite. This seal was chosen because of its low friction characteristics. The size of silicone rubber seal is $\emptyset 24 \times \varnothing 16 \times 4.5 \mathrm{~mm}$ and its hardness is of $50^{\circ}$. It was chosen because of good hardness and compressibility properties. The size of O-ring seal of nitrile rubber is $\emptyset 24 \times \varnothing 16 \times 4 \mathrm{~mm}$, selected because of its good compressibility and chemical strength. The nitrile rubber O-ring seal combined with a plastic nylon washer as shown in Fig. 11 was used.

\subsection{Experimental Results and Discussion}

With the soft wiper seal, after $5 \mathrm{~km}$ of moving the oil hydraulic cylinder, the component became ineffective due to wear of seal. Lots of dust entered the system and degraded the hydraulic oil, filter element and increased pressure. With the silicon rubber seal, it was torn during the preliminary tests. For O-ring seal, after the oil hydraulic cylinder moved $10 \mathrm{~km}$, there was no increase in pressure. However, the hydraulic oil and filter element became dirty. The cause of limited performance of the component when inserted with O-ring seal was discussed. All the component parts including the seal were in good condition with no damage and no change in dimensions of the seal after the test. The clearance between the seal and oil hydraulic cylinder rod was 
tight enough. However, the seal seemed to have uneven contact with the metal lid. Thus, this could have caused the seal to become unstable gradually in its groove due to the contact force the hydraulic cylinder rod subjects to it during reciprocating motion. As a result, this seems to create a clearance between the inside of O-ring and the rod during reciprocating motion.

To prevent this phenomenon, a nylon plastic washer $\varnothing 28 \times \emptyset 17 \times 0.5 \mathrm{~mm}$ was inserted on the top of the O-ring seal before covering with the steel metal lid as demonstrated in Fig. 11. The material of the washer was chosen because of its lightweight, toughness and chemical resistance. The purpose of the washer was to provide uniform and extra support to the O-ring seal in addition to the steel metal lid. This would tightly secure the seal in position, improve its stability and prevent it from attempting to move. More so, the internal diameter of the O-ring seal was coated with fluorine coating agent to smoothen its surface and reduce sliding friction.

Figs. 12 and 13 show the results of filter element, hydraulic oil and pressure, after inserting washer together with O-ring seal in the component. Basing on the colours of filter element and hydraulic oil shown in Fig. 12, almost no dust entered the oil hydraulic system until about $40 \mathrm{~km}$. From $50 \mathrm{~km}$ onwards, the colour changes show clear evidence of dust entry into the hydraulic system. In Fig. 13, it can be noted that prior to $40 \mathrm{~km}$, there was continuous decrease in pressure. This is because, at the time of conducting experiments, the filter was periodically checked to establish the condition of oil and filter element. In the process of returning the oil, drops of it adhered to the walls of container. This led to reduction of oil in the system hence lowering pressure in the system. However, after $40 \mathrm{~km}$, pressure starts to increase expressly. This is in agreement with the results of hydraulic oil and filter element where entry of dust is clearly noticeable after $40 \mathrm{~km}$. Therefore, basing on the results, the proposed component can be used at least until about $40 \mathrm{~km}$ or for 100 hours before repair.

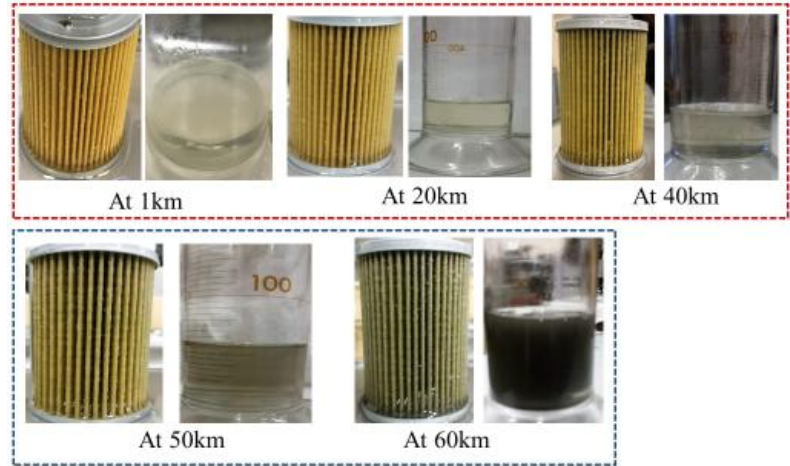

Fig. 12 Filter element and hydraulic oil after the test.

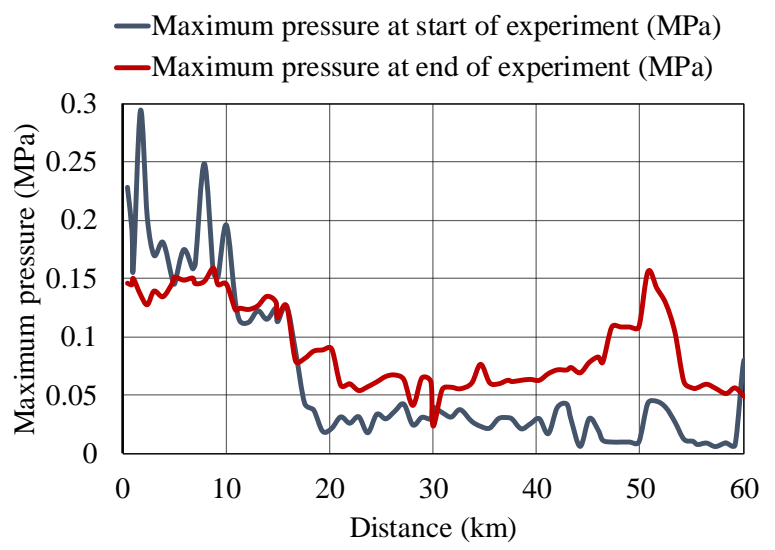

(a) Maximum pressure vs distance

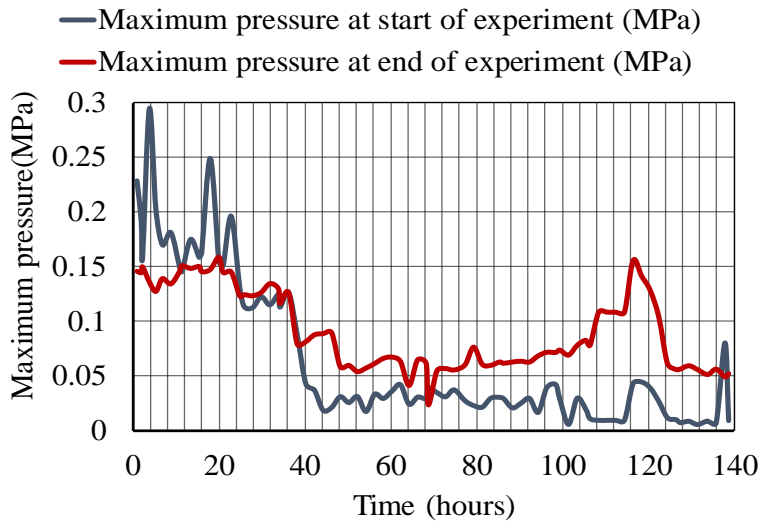

(b) Maximum pressure vs. time

Fig. 13 Maximum pressure at the rod side end of hydraulic cylinder.

\subsection{Friction Characteristics of O-ring Seal Combined with a Plastic Nylon Washer}

When the component is connected to the hydraulic cylinder, the contact force between the rod and seals increases due to the additional seal and washer in the component. This leads to increase in friction, which 
can affect sliding. Thus, the friction characteristics of the component were investigated.

To do so, the value of average current supplied to the motor of electric cylinder was measured using a digital multimeter during reciprocating motion since current supply to the motor varies with load. At a pressure of $0.23 \mathrm{MPa}$, two experiments were conducted, before and after mounting the component when inserted with O-ring seal combined with a plastic nylon washer on hydraulic cylinder. Then, average current $I_{\mathrm{b}}$ before mounting the component and average current $I_{\mathrm{a}}$ after mounting the component were measured. Based on many experiments, $I_{\mathrm{b}}$ was 0.361 A and $I_{\mathrm{a}}$ was $0.377 \mathrm{~A}$, that is $I_{\mathrm{a}}$ is $1.04 \%$ greater than $I_{\mathrm{b}}$. Therefore, when the component is employed, it can be deduced that the friction is not increased largely and the component has good friction characteristics.

\section{Conclusion}

In this study, a component to prevent entry of dust into the oil hydraulic system through the rod-seal clearance of the oil hydraulic cylinder was proposed, fabricated and its performance was tested by fitting it on to the rod side end of the oil hydraulic cylinder. Thus, the study aims to address a crucial problem of contamination of oil hydraulic systems by dust, which has always shortened their durability.

Firstly, an experiment apparatus is proposed and used to simulate the intrusion of dust into the hydraulic system through the rod seal clearance of the hydraulic cylinder. After $100 \mathrm{~km}$, a lot of dust put on the rod of the oil hydraulic cylinder during the experiments entered the oil hydraulic system, greatly dirtied the filter element, hydraulic oil and lowered their performance, and this led to an increase in system pressure. For this reason, simulation of intrusion of dust through the rod seal clearance of the hydraulic cylinder was completed successfully. Therefore, it is known that the proposed experimental apparatus is suitable as a simulator to realize the intrusion of dust. The proposed component was then fabricated and tested for performance when inserted with various elastic rings. The component gives most tremendous results when inserted with O-ring seal and nylon plastic washer. It can be used at least until about $40 \mathrm{~km}$ or 100 hours before repair. The component also has good friction characteristics. It can be retrofitted on both new and old oil hydraulic cylinders to prevent dust from entering the oil hydraulic system. Once adopted, it can help to reduce the breakdown rate and prolong the life span of oil hydraulic systems. It is very suitable for use globally especially in low developing countries where dust is still a major concern. Moreover, its fabrication, usage and maintenance are easy due to its simple structure.

\section{Acknowledgment}

The authors would like to express their appreciation to Mr. Okamoto and Mr. Okada, students of Ashikaga University at that time.

\section{References}

[1] Zhao, X., Hu, Z., and Shang, Y. 2013. "Research on Hydraulic Cylinder Fault Diagnosis System Based on ARM." Advanced Materials Research 619: 489-93.

[2] Zhong, Z., Zhu, Y., and Zhang, Y. 2012. "Experiments on Effects of Dust Particles on the Wear of Cylinder Liner in Internal Combustion Engine." Industrial Lubrication and Tribology 64 (6): 321-30.

[3] Related Fluid Power. 2017. "DC Power Units, Contamination and Oil Cleanliness." https://www.relatedfluidpower.com/wp-content/uploads/2 017/09/Contamination-Oil-Cleanliness.pdf.

[4] Flow Ezy Filter Notes. 2008. "How Dirt Levels Affect Hydraulic System Performance." https://www.flowezyfilters.com/pdfs/how\%20dirt\%20lev els $\% 20$ affect $\% 20$ hydraulic $\% 20$ system $\% 20$ performance.p df.

[5] Parker Hydraulics. "Hydraulic Cylinder Trouble Shooting-Avoiding Rod Seal Leakage and Pre-mature Ware.” Bulletin1242/1-GB. https://www.parker.com/literature/Literature\%20Files/eur o_cylinder/v4/Trouble_1242-1-gb.pdf.

[6] Yuwono, A. S., Khoirunnisa, F., Fauzan, M., Iskandar, and Regia, R. A. 2017. "Reduction of Dustfall and Total Suspended Particulate (TSP) Generation from Alluvial Soil Surface." International Journal of Applied Environmental Sciences 12 (11):1927-38. 